Astronomy with the Fleurs six-dish array

An 'X-banded' Tidbinbilla interferometer

\section{History of Australian Astronomy}

John Tebbutt's observations of Halley's Comet in 1910

Other Submission

Galactic Halo

Neutral hydrogen in the galactic halo

Book Reviews

Standard Handbook for Telescope Making

Superforce-search for a GUT of nature

Supernovae

Cambridge Astronomy Guide

Astrophotography for the amateur

The Crab Nebula and related supernova remnants

Spherical astronomy
Michael J. Batty, John D. Bunton,

David R. Brown, Julian B. Corbin and Graeme L. White

Michael J. Batty, R. G. Gardyne,

G. J. Gay, S. Gulkis, David L.

Jauncey, A. Kirk and W. L. Peters

S. Röser and Graeme L. White

354

R. X. McGee and Lynette M. Newton

Reviewer

L. R. Allen

385

R. J-M. Grognard 385

J. L. Caswell 386

R. P. Norris 387

G. L. White 387

J. A. Roberts

W. J. Tango 389

Notice to Authors

Cover

White Cliffs solar power station used for gamma-ray astronomy by University of Adelaide. 


\section{Astronomical Society of Australia}

Proceedings

Volume 6 Number 31986

Invited Papers Gamma-ray astronomy at the highest energies

R. J. Protheroe

The Australia Telescope Project: Going along nicely thank you!

\section{Contributions Comets}

The Giotto radio science experiment at Parkes

P. J. Hall

Observations of $18 \mathrm{~cm} \mathrm{OH}$ emission and absorption from Halley's Comet

R. A. Duncan, R. P. Norris J. R. Forster, R. T. Stewart

Meteors

Frequency dependence of radar meteor echo rates and D. McConnell

R. M. Thomas, P. S. Whitham, and W. G. Elford

Stars

Simultaneous infrared \& optical photometry of the eclipsing dwarf V2051 Ophiuchi

Fast $\mathrm{H} \alpha$ variations in a rapidly rotating spotted star

D. J. Watts and R. D. Watson

R. D. Robinson and A.

Collier-Cameron

O. B. Slee, G. J. Nelson, J. L.

The active radio star $\mathrm{HD} 36705$

Innes, R. T. Stewart, A. E. Vaughan and A. E. Wright

Radio emission from starspots on RSCVn binary HR1099

John D. Bunton, R. T. Stewart

O. B. Slee, G. J. Nelson, Alan E. Wright, Julian B. Corbin, David R.

Brown and P. J. Hall

A search for $843 \mathrm{Mhz}$ radio emission from active stars A. E. Vaughan and M. I. Large

\section{Theoretical}

A non-linear bifurcation in cellular convection theory

N. Yannios, J. M. Lopez and

J. O. Murphy

Radio astronomy extragalactic

Radio Continium emission from Sculptor galaxies 1452-517: a giant radio galaxy at low galactic latitude

J. I. Harnett

Radio astronomy low frequency

Radio astronomy through an artificial ionospheric window Spacelab 2 observations

P. A. Jones

Observations of $1.91 \mathrm{Mhz}$ echoes from the magnetic conjugate

point after propagation through a magneto-ionic duct

G. R. A. Ellis, A. Klekociuk,

G. T. Goldstone and M. Medillo

G. T. Goldstone and G. R. A. Ellis

Gamma-ray astronomy

Development of the Buckland Park cosmic ray air shower array for ultra high energy gamma-ray astronomy

D. Ciampa, R. W. Clay, C. L. Corain, P. G. Edwards and J. R. Patterson

Very high energy gamma-ray astronomy at White Cliffs solar R. W. Clay, S. D. Elton, A. G. power station Gregory, J. R. Patterson and R. J. Protheroe

\section{Instrumental}

Astronomical Co-ordinates at the Parkes radio-telescope D. McConnell 